\title{
Nitric Oxide-Induced Nitrative Stress Involved in Microbial Pathogenesis
}

\author{
Mohammad Hasan Zaki ${ }^{1}$, Teruo Akuta ${ }^{1}$, and Takaaki Akaike ${ }^{1, *}$ \\ ${ }^{1}$ Department of Microbiology, Graduate School of Medical Sciences, Kumamoto University, \\ Honjo 1-1-1, Kumamoto 860-8556, Japan
}

Received March 30, 2005

\begin{abstract}
The pathogenic mechanism of infections is a complicated but important scientific theme that is now attracting great attention because of its association with host-derived as well as microbial factors. Recent advances in free radical research revealed that reactive oxygen and nitrogen oxide species such as superoxide $\left(\mathrm{O}_{2}^{-}\right)$and nitric oxide (NO) play a leading role in the pathogenesis of infections caused by viral pathogens including influenza virus and other RNA viruses. Although $\mathrm{NO}$ and $\mathrm{O}_{2}^{-}$have antimicrobial activity against bacteria, fungi, and parasites, in some viral infections they have an opposite effect. This exacerbation caused by $\mathrm{NO}$ and $\mathrm{O}_{2}{ }^{-}$ is mediated by reactive nitrogen oxides, for example, peroxynitrite $\left(\mathrm{ONOO}^{-}\right)$, generated by reaction of $\mathrm{NO}$ with $\mathrm{O}_{2}^{-}$. These nitrogen oxides have strong oxidation and nitration potential and can modify biological molecules, thereby creating oxidative and nitrative stress that contributes to pathogenic processes during viral infection. Nitrative stress-mediated 8-nitroguanosine formation during influenza or Sendai virus infection has been the focus of enormous interest because it involves unique biochemical and pharmacological properties such as redox activity and mutagenic potential. In this review, we discuss the nature and impact of nitrative stress in viral infection, with emphasis on nitrative stress-mediated viral pathogenesis, which we have recently been investigating.
\end{abstract}

Keywords: nitric oxide, peroxynitrite, nitrative stress, 8-nitroguanosine, viral pathogenesis, viral mutation

\section{Introduction}

Nitric oxide (NO) is a gaseous free radical species with pleiotropic functions in pathophysiology. NO is synthesized by means of an enzymatic reaction involving two-step oxidation of the terminal guanidine nitrogen of L-arginine, the result being formation of $\mathrm{NO}$ and L-citrulline (1). The enzymes involved in this catalytic reaction are NO synthases (NOSs), which are expressed both as constitutive enzymes, produced primarily in endothelial cells (eNOS) and neuronal cells (nNOS), and as an inducible isoform (iNOS). Constitutively produced NOSs contribute to several physiological processes including vasorelaxation and neurotransmission. In contrast, iNOS, which is expressed in various cells

*Corresponding author. FAX: +81-96-362-8362

E-mail: takakaik@gpo.kumamoto-u.ac.jp

Invited article including macrophages, neutrophils, epithelial cells, and hepatocytes, produces excessive NO during infections, inflammation, and states of physiological stimulation $(2,3)$.

During microbial infections, excessive NO produced by iNOS has diverse functions ranging from antimicrobial and antiinflammatory host defense and cytoprotection to proinflammatory and cytotoxic activities. The nature of the pathological insults and the physiological environment of infections govern which of two opposite roles NO will play: either defense of the host or impairment of host defense so that pathogenesis of the invading microbes is supported. The host defense function of NO is best characterized by antimicrobial and cytoprotective activities that have been observed in bacterial, fungal, and parasitic infections (4-7). In contrast, NO-mediated inflammation and pathogenesis have been documented in several diseases including arthritis, encephalitis, ulcerative colitis, and viral infections $(2,8-10)$. In these NO-related disorders, NO is 
most important in viral infections, even though nonspecific antiviral effects have been reported for certain infections, because it promotes the viral pathogenesis.

The multiple biological effects of NO depend on the nature of its reactions in the biological milieu under various pathophysiological conditions. The chemical and biological reactivities of NO produced in inflamed tissues during infection or inflammation are greatly affected by concomitant production of oxygen radicals, particularly superoxide $\left(\mathrm{O}_{2}^{-}\right)$and hydrogen peroxide. The interaction of NO with reactive oxygen species causes formation of several reactive nitrogen oxides, such as peroxynitrite $\left(\mathrm{ONOO}^{-}\right)$and nitrogen dioxide. These reactive nitrogen intermediates have great potential to cause oxidative and nitrative stress by means of oxidation and nitration of biological molecules including proteins, nucleic acids, and membrane lipids. Oxidation and nitration reactions mediated by the reactive nitrogen and oxygen species apparently affect both the host and the pathogen in a nonselective manner and play an important role in innate host defense. Nitrative stress generated during infection and inflammation has recently been the focus of great attention because of its association with the pathogenesis of infectious diseases such as viral pneumonia, Helicobacter pylori infection, and Opisthorchis viverrini infection in hamsters $(11-13)$. Moreover, nitrative stress was reportedly involved in viral mutation and evolution, which are closely related to mechanisms of disease pathogenesis and outbreaks of emerging or re-emerging infections $(14,15)$.

Because a delicate balance between host and pathogen interactions determines the pathological consequences of microbial infections, a central theme in modern medical research is understanding of the host-pathogen interaction rather than gaining insight into a particular microbe. In this context, better understanding of the molecular mechanism of the unique pathogenic principle mediated by NO during microbial infections would help stimulate new scientific research, not only on microbiology and infectious disease but also on other related areas such as biochemistry and pharmacology. We have been working for some time on oxygen radical- and NOinduced viral pathogenesis caused by neurotropic or pneumotropic viruses such as herpes simplex virus (HSV) and influenza virus in several animal models. In this review, we discuss the nature and impact of nitrative stress in microbial pathogenesis, with special emphasis on underlying mechanisms that we have observed in recent investigations.

\section{Beneficial aspects of NO in microbial infections}

NO was first described as a gaseous signal molecule with fuctions in several physiological phenomena, including smooth muscle relaxation, neurotransmission, tissue homeostasis, memory and learning processes, and inhibition of platelet aggregation. It is now well known, however, that a large amount of NO is produced during microbial infections caused by almost all pathogens including bacteria, viruses, parasites, and fungi (4-7, 16). In infections with Salmonella, Mycobacterium, Leishmania, Streptococcus, and Bordetella, excessive NO is produced after induction of iNOS. In most cases, this excessive production of NO results in innate resistance against these bacteria. In a study of Bordetella pertussis in wild-type $\left(\mathrm{iNOS}^{+/+}\right)$and iNOS-deficient $\left(\mathrm{iNOS}^{--}\right)$mice, increased bacterial growth and higher susceptibility to infection were found in $\mathrm{iNOS}^{-/-}$mice compared with wild-type mice (17). Our study using an $\mathrm{NO}$ inhibitor and $\mathrm{iNOS}^{-/-}$mice unequivocally established a similar protective role of NO in murine salmonellosis $(6,18)$. An absence of NO synthesis was associated with greater bacterial growth, increased apoptosis, and exacerbation of pathological characteristics in mouse liver infected with Salmonella enterica serovar Typhimurium (18).

However, in Mycobacterium infection, $\mathrm{NO}$ has diverse roles. Different species of Mycobacterium have demonstrated variations in susceptibility to $\mathrm{NO}$ and its reactive intermediates. For example, activated mouse macrophages inhibited growth of Mycobacterium leprae and Mycobacterium tuberculosis (19, 20). Flesch et al. reported that intracellular growth of Mycobacterium bovis and M. tuberculosis $\mathrm{H} 37 \mathrm{Rv}$ was inhibited by reactive nitrogen intermediates generated from bone marrow-derived macrophages (21). A contrasting result was observed for Mycobacterium avium: in one experiment, mouse peritoneal macrophages and human monocyte-derived macrophages were infected with M. avium and were then stimulated with interferon (IFN)- $\gamma$, tumor necrosis factor (TNF)- $\alpha$, and granulocytemacrophage colony-stimulating factor in the presence or absence of $N^{\omega}$-monomethyl-L-arginine (L-NMMA) or arginase. Neither competitive inhibition by L-NMMA nor depletion of L-arginine by arginase had any effect on inhibition of growth of M. avium (22). In our laboratory, we examined the effect of $\mathrm{NO}$ on intracellular growth of M. avium complex (MAC: one strain of M. avium and two strains of Mycobacterium intracellulare). Rat alveolar macrophages were infected with MAC in the presence or absence of L-arginine or L-NMMA and were then stimulated with IFN- $\gamma$. After 3 days of incubation, the number of viable intracellular Mycobacterium 
organisms was measured by means of the colony-forming assay and the amount of NO was determined by assay of $\mathrm{NO}_{2}^{-}$in the culture supernatant. In brief, we found that growth of $M$. avium MiNO was significantly inhibited by NO synthesized from L-arginine in the cells. However, we found no significant inhibitory effects of NO on growth of the two $M$. intracellulare strains that were eventually much less susceptible to $\mathrm{NO}$ and its reactive intermediates than was $M$. avium MiNO (5).

As found for bacterial infections, iNOS-mediated NO production has been documented in several experimental viral infections in mice and rats, including those with neuroviruses, such as Borna disease virus, HSV-1, and rabies virus, and pneumotropic and cardiotropic viruses, such as influenza virus, Sendai virus $(\mathrm{SeV})$, and coxsackievirus $(23-28)$. iNOS expression was also observed in human diseases caused by human immunodeficiency virus-1 (HIV-1) and hepatitis B virus (HBV) $(29,30)$. Thus, iNOS is ubiquitously expressed during host responses to microbial propagation and invasion.

However, the precise role of $\mathrm{NO}$ in viral infection remained unclear. In infections with certain viruses, for example, coxsackievirus $(31,32)$, Epstein-Barr virus (33), and HSV-1, NO inhibited viral propagation (26, $34,35)$. Despite the antiviral activity of NO, induction of NO synthesis is not always beneficial; rather NO promotes the pathogenesis of some viral infections, such as influenza, tick-born virus infection, HSV-1 infection, and cytomegalovirus (CMV) infection. In these diseases, $\mathrm{NO}$ and its reactive species were associated with damage to cells in host tissue, which aided the infection. Thus, the role of NO in viral pathogenesis deserves special attention so as to achieve complete understanding of host-pathogen interactions during viral infection.

\section{NO production in viral infections}

During viral infection, as in other microbial infections, NO is produced in macrophages and phagocytic cells as an innate host defense mechanism. The enzyme responsible for this infection-induced NO production is iNOS. Studies of the molecular mechanism of iNOS induction revealed that several cytokines including IFN- $\gamma$, TNF- $\alpha$, and interleukin (IL)-1 are responsible for this induction, with IFN- $\gamma$ playing the pivotal role (36, 37). A study with mouse peritoneal macrophages found that HSV-2 infection acted in synergy with IFN- $\gamma$ to induce NO production (38). We observed marked attenuation of NO production in IFN- $\gamma$-deficient mice infected with influenza virus or $\mathrm{SeV}$ (T. Akaike et al., unpublished observation). Furthermore, the iNOS-inducing potential in bronchoalveolar lavage fluid in influenza virus pneumonia was attributable solely to IFN- $\gamma$, as revealed by an immunoadsorption study with a specific anti-IFN- $\gamma$ antibody (10). These results indicate that IFN- $\gamma$ is a cytokine of major importance for inducing iNOS and NO overproduction during viral infections.

Induction of iNOS by IFN- $\gamma$ occurs at transcriptional levels (39). The promoter of the iNOS gene has two nuclear factor $-\kappa \mathrm{B}(\mathrm{NF}-\kappa \mathrm{B})$ binding sites and an IFNstimulated response element, to which interferon regulatory factor-1 (IRF-1) binds (37). Researchers have found that $\mathrm{NF}-\kappa \mathrm{B}$ and IRF-1 are two transcriptional factors that participate in gene activation in response to viral infection or dsRNA $(40-42)$. Both IRF-1 and $\mathrm{NF}-\kappa \mathrm{B}$ have been shown to physically interact at the iNOS promoter region, which may lead to the synergistic activation of iNOS expression observed when both transcriptional factors are activated (43). IRF-1 is an inducible transcriptional factor expressed in response to IFN- $\gamma$, viral infection, dsRNA, cytokines IL-1 and IL-6, and TNF- $\alpha$ (41). In contrast to IRF-1 activation by IFN $-\gamma, \mathrm{NF}-\kappa \mathrm{B}$ is activated mainly by lipopolysaccharide (37). However, in viral infection, a mechanism mediated by TNF- $\alpha$ is involved in NF- $\kappa \mathrm{B}-$ activated iNOS induction. Baskin et al. demonstrated that IFN- $\gamma$ acts in synergy with TNF- $\alpha$ to produce NO in HSV-2 infection (38). Subsequent studies revealed that the synergistic effect of TNF- $\alpha$ is mediated by NF- $\kappa \mathrm{B}$ activation, which is itself responsible for synergistic production of high-output NO by HSV-2 and IFN- $\gamma$ (44).

Certain other cytokines, for example, IL-4, IL-10, IL-13, and transforming growth factor- $\beta$, participate in down-regulation of iNOS expression $(45-47)$. These suppressor cytokines may reduce NO production directly by inhibiting iNOS-inducing cytokines or indirectly via induction of arginase $(48,49)$, which reduces the supply of the substrate (L-arginine) for iNOS. In fact, the iNOS-inducing cytokines IFN- $\gamma$ and TNF- $\alpha$ are proinflammatory cytokines produced by subset 1 of helper T cells (Th1). Th1 cells are primarily responsible for innate and humoral immunity against viral infection. Th2 cells, in contrast, produce cytokines that are antagonistic to iNOS induction. An important function of cytokines produced by the Th2 family is inhibition of Th1-mediated cytokine induction. This finding was supported by our influenza model study in which induction of IL-4 seemed to be inversely related to IFN$\gamma$ and iNOS induction in virus-infected lungs, which suggested down-regulation by IL-4 of NO overproduction (50). The mechanism of IL-4- and possibly IL-13mediated inhibition of iNOS activation is induction of factors that interfere with IRF-1 function $(51,52)$. Because IL-4, IL-10, and IL-13 are induced by Th2 cell responses, iNOS expression may be regulated by a Th1-Th2 balance during the host immune response to 
invading virus.

In some viral diseases, viral replication or viral components directly induce iNOS without mediation by proinflammatory cytokines. iNOS expression in HIV encephalitis is of particular interest in this regard (29). An envelope glycoprotein of HIV, gp41, triggers iNOS expression in human astrocytes and murine cortical brain cells in culture $(53,54)$. Thus, NO produced by iNOS may contribute directly to pathogenesis of HIVassociated dementia and cardiomyopathy (29, $53-55)$. Similarly, the human paramyxovirus respiratory syncytial virus directly up-regulates iNOS in human type 2 alveolar epithelial cells through a pathway independent of proinflammatory cytokines (56). Two pathways for iNOS induction therefore operate in viral infections: cytokine-dependent mechanisms and direct up-regulation by virus.

\section{Role of NO in viral pathogenesis}

As mentioned above, NO has dual functions in viral infection. As an effector molecule produced by phagocytic cells, NO has antiviral activity, which was described in some studies. However, unlike the antibacterial activity of $\mathrm{NO}$, the antiviral activity of $\mathrm{NO}$ was associated with nonspecific damage of host cells and tissues, which led to an exacerbation of viral patho- genesis in many infections. Therefore, in spite of NO's antiviral activity, excessive production of $\mathrm{NO}$ may facilitate viral pathogenesis. This suggestion was best demonstrated in a series of our investigations on influenza virus infection in mice. We found iNOS to be expressed in bronchial epithelial cells and macrophages in the lung, and NO production paralleled the iNOS induction. The time profile of iNOS induction in the lung correlated well with that of pulmonary consolidation rather than that of viral replication (10). To directly establish NO overproduction in the mouse lung after infection with influenza virus, lung tissue was analyzed via electron spin resonance (ESR) with a dithiocarbamate and iron complex as a spin trap for NO. NO generation was detected by means of formation of an NOdithiocarbamate-iron adduct possessing a triplet hyperfine structure of $g$ perpendicular equal to $2.04(57,58)$. However, inhibition of NO by L-NMMA treatment of the influenza virus-infected mice resulted in significant improvement in survival rate (10). NO-mediated pathogenesis of murine pneumonia caused by influenza virus or $\mathrm{SeV}$ was further examined by using $\mathrm{iNOS}^{-/-}$ mice. Consistent with our previous results, a significant improvement in survival as well as reduced pathological change in the lung was found in both $\mathrm{iNOS}^{-/-}$and $\mathrm{iNOS}^{+/-}$mice compared with $\mathrm{iNOS}^{+/+}$mice (Fig. 1) (11). $\mathrm{iNOS}^{+/+}$mice infected with influenza virus or $\mathrm{SeV}$ had

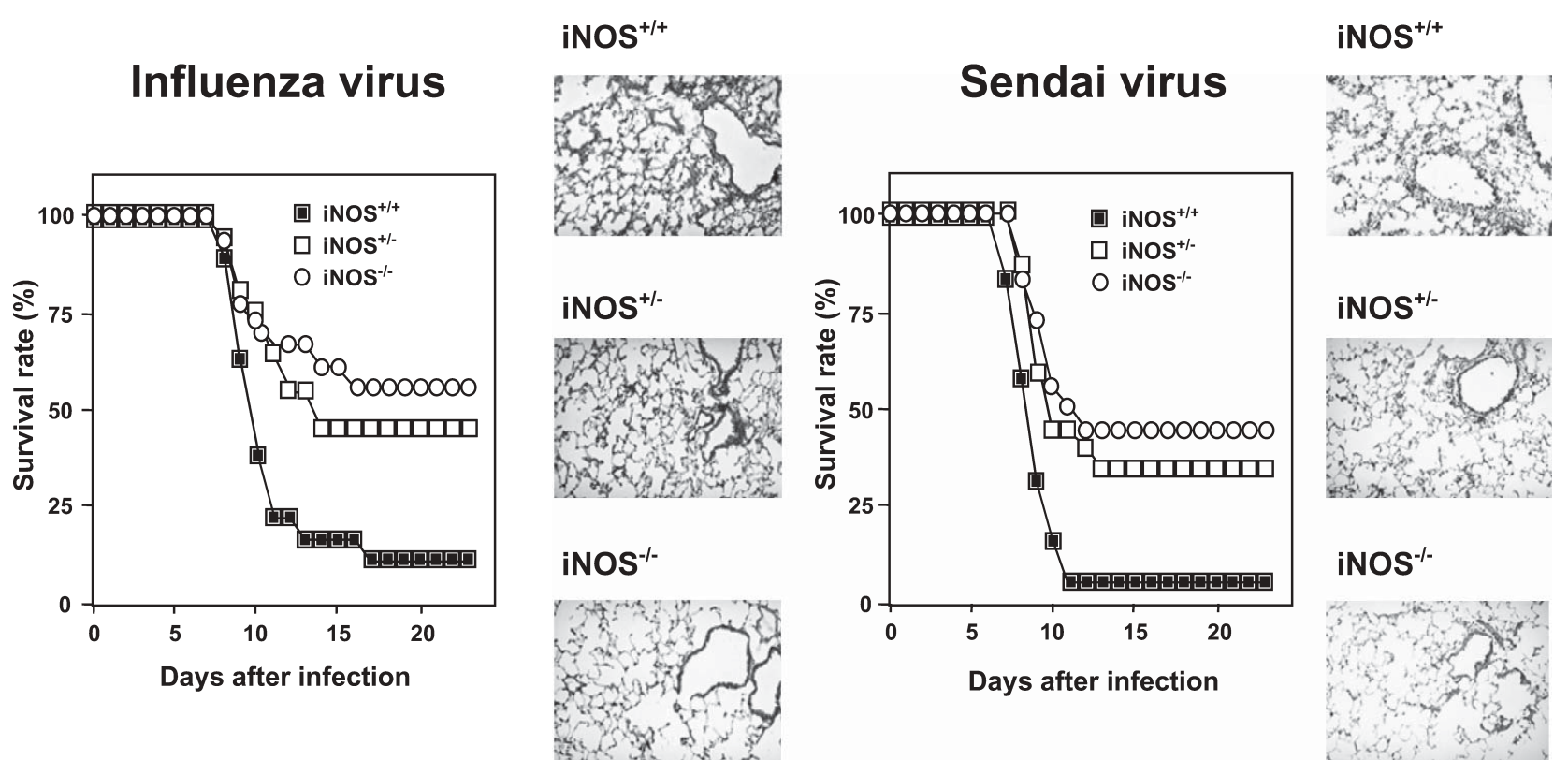

Fig. 1. Survival and pathological pulmonary changes in wild-type $\left(\mathrm{iNOS}^{+/+}\right)$and $\mathrm{iNOS}^{-/-}$mice after influenza virus and $\mathrm{SeV}$ infections. iNOS ${ }^{+/+}$, heterozygous iNOS-deficient $\left(\mathrm{iNOS}^{+/-}\right)$, and homozygous iNOS-deficient $\left(\mathrm{iNOS}^{-/-}\right)$mice were infected with influenza virus A/Kumamoto/Y5/67(H2N2) or $\mathrm{SeV} \mathrm{Z} \mathrm{strain} \mathrm{by} \mathrm{inhalation} \mathrm{of} \mathrm{viral} \mathrm{suspension} \mathrm{at} 2 \times \mathrm{LD}_{50}$ dose. Survival (left panels) was monitored, and histopathological changes in the lung (right panels) at 8 days after infection were examined by using hematoxylin and eosin staining. Adapted from Ref. 11. 
extensive inflammatory cell infiltration and alveolar exudates as well as destruction of pulmonary architecture; in $\mathrm{iNOS}^{-/-}$mice, these changes were significantly reduced (Fig. 1). Kreil and Eibl obtained similar results concerning the effect of NOS inhibition on tick-borne encephalitis (TBE) in mice (59). They reported that excessive NO production in murine macrophages did not inhibit TBE virus replication. Treatment of the TBE virus-infected mice with the NOS inhibitor aminoguanidine, however, produced a significantly increased survival time.

HSV-1 infection is another example of an NOmediated viral disease, although antiviral activity of NO against HSV-1 has been observed in some in vitro studies. We examined the effect of NO on HSV-1 encephalitis in Lewis rats. After 4 days of infection, HSV-1 was detected in four regions of the brain: olfactory bulb, brain stem, cerebellum, and cerebrum. iNOS expression in these areas was also observed, but not until day 4. iNOS mRNA was expressed on days 5 and 6 , and the pattern of iNOS expression was quite similar to the pattern of virus yield (28). The time profile of NO production was measured by using ESR spectroscopy and was found to parallel that of iNOS mRNA expression and HSV replication in the olfactory bulbs and brain stem. To clarify the role of NO in HSV-1 infection, the NO inhibitor L-NMMA was administered to HSV-1-infected rats after 3 days of infection. Survival was significantly improved by NO inhibition, but with no significant reduction in viral yield. These data strongly suggested that the pathological events in HSV-1-induced encephalitis are closely linked not only to the direct cytopathic effect of HSV-1 but also to NO-induced cytotoxicity mediated by host responses (28). Adler et al. reported similar results for the effect of NO in HSV-1-induced pneumonia (60). They observed that L-NMMA treatment led to significant improvement in pneumonia caused by HSV-1 despite increased growth of virus in the lung. Thus, we conclude from all these reports that NO-mediated cytotoxicity and pathogenesis are the dominant functions of NO, rather than its antiviral effect, in HSV-1 infections.

NO-mediated pathogenesis was also noted in other viral diseases, including murine CMV infection $(61,62)$. At 4 weeks after CMV infection in BALB/c mice, no virus was detected in the lung and liver; a few viruses were found in the salivary gland. Acute pneumonia was developed when the $\mathrm{T}$ cells of the mice, which had been infected with murine CMV 4 weeks earlier, were activated by a single dose of anti-CD3 monoclonal antibody. The degree of this T-cell activation-mediated pulmonary disorder was found to parallel with the NO production induced by the proinflammatory cytokines INF- $\gamma$ and TNF- $\alpha$ that were secreted on T cell activation. The apparent correlation of NO production with this pneumonia was further clarified by administration of an NO inhibitor $N^{\omega}$-nitro-L-arginine methyl ester or phenyl $N$-tert-butyl nitrone, which led to marked improvement in the pulmonary lesions (61). The correlation between iNOS expression and the pathogenesis of chronic hepatitis caused by HBV and hepatitis $\mathrm{C}$ virus was studied by Kandemir et al. (63). They found that elevated iNOS expression and NO-mediated nitration of hepatocellular protein were correlated with disease severity. All these data thus demonstrated that in viral infection, NO is overproduced via iNOS induction, but this effect is not always associated with protection of the host, as is the case in bacterial and parasitic infections. Rather, in viral infections NO has a critical role in inflammation and pathogenesis.

\section{Development of nitrative stress during viral infections}

NO itself is an inert radical and much less reactive compared with other naturally occurring oxygen and alkyl radicals $(64-66)$. NO-mediated cytotoxicity depends on the reaction of $\mathrm{NO}$ with oxygen radicals, particularly $\mathrm{O}_{2}^{-}$, to produce $\mathrm{ONOO}^{-}$and other reactive nitrogen oxides including nitrogen dioxide $\left(\mathrm{NO}_{2}\right)$. The groups of Eiserich, van der Vliet, and others demonstrated that reactive nitrogen species such as $\mathrm{NO}_{2}$ are also produced by the reaction of nitrite with the $\mathrm{H}_{2} \mathrm{O}_{2}$ myeloperoxidase system $(67,68)$. A similar reaction producing reactive nitrogen oxides is catalyzed by other peroxidases including that of eosinophils. Reactive nitrogen oxides thus produced have strong oxidation and nitration potentials. For example, $\mathrm{ONOO}^{-}$has been implicated as a mediator of pathogenesis in a number of disorders such as ishchemia-reperfusion, sepsis, arthritis, and pneumonia (65). The cytotoxicity of $\mathrm{ONOO}^{-}$is based on its ability to react with biological targets including thiols, iron-sulfur centers, proteins, nucleic acids, and lipids. In biological systems, $\mathrm{ONOO}^{-}$ can exist as a so-called solvent-caged radical formed from hydroxyl radical and nitrogen dioxide, which are also strong oxidants and nitrating agents of biological molecules. In bacterial infections, $\mathrm{ONOO}^{-}$can exert its antimicrobial activity directly in confined areas of septic foci. In contrast, in viral infections, $\mathrm{NO}$ and $\mathrm{ONOO}^{-}$, which are primitive and nonselective host defense molecules, cause oxidative and nitrative damage in virus-infected tissues, which leads in turn to various pathological events. In this case, virus cannot be confined to limited areas by the nonspecific host defense system that is mediated by phagocytes, $\mathrm{NO}$, and $\mathrm{O}_{2}^{-}$. 
One of the most important nitration reactions effected by $\mathrm{ONOO}^{-}$and $\mathrm{NO}_{2}$ in biological systems is tyrosine nitration, with formation of 3-nitrotyrosine. Data have documented production of 3-nitrotyrosine by $\mathrm{ONOO}^{-}$ in a variety of proteins through a reaction catalyzed by heavy metals such as iron and copper. Increased 3nitrotyrosine formation has been found in acute lung injury, sepsis, rheumatoid arthritis, Alzheimer disease, and liver transplantation $(65,69)$. We also provided the first demonstration of involvement of $\mathrm{NO}$ in viral pathogenesis by formation of $\mathrm{ONOO}^{-}$and other reactive nitrogen oxide species in a study of murine pneumonia caused by influenza virus (10), the pathogenic roles of oxygen radicals having been suggested by our earlier studies $(70,71)$. In fact, production of $\mathrm{NO}$ and $\mathrm{O}_{2}^{-}$ with formation of $\mathrm{ONOO}^{-}$in viral pneumonia was found to contribute to severe lung injury, as evidenced by immunohistochemical detection of 3-nitrotyrosine. Strong immunohistochemical staining for 3-nitrotyrosine was observed in macrophages and neutrophils infiltrating the alveolar lumens of lungs of ddY mice after infection with influenza virus. Also, some intraalveolar exudates in the virus-infected lung were strongly positive for 3-nitrotyrosine.

In addition, we investigated NO-dependent 3-nitrotyrosine formation in lung tissues in $\mathrm{iNOS}^{+/+}, \mathrm{iNOS}^{+/-}$, and $\mathrm{iNOS}^{-/-}$mice with pneumonia caused by influenza virus or $\mathrm{SeV}$ (11). Immunohistochemical analysis as well as high-performance liquid chromatography coupled with electrochemical detection of 3-nitrotyrosine in bronchoalveolar lavage fluid from virusinfected lung provided a quantitative yield of 3-nitrotyrosine. The amount of 3-nitrotyrosine formed in the lungs of wild-type mice increased in a time-dependent manner after viral infection, which correlated well with NO production as assessed by ESR. However, 3-nitrotyrosine was not detected at any stage of infection in $\mathrm{iNOS}^{-/-}$mice. A moderate level of 3-nitrotyrosine was formed in lung tissue from iNOS ${ }^{+-}$mice. Similar NOmediated formation of 3-nitrotyrosine in lung tissue was observed in murine CMV-associated pneumonia, as just mentioned (62). Although the exact role of 3nitrotyrosine in the pathogenesis of pneumonia caused by these viruses has not been clearly defined, the occurrence of 3-nitrotyrosine formation in the infected tissues at least provides evidence of nitrative stress in viral pathogenesis.

Protein nitration as indicated by formation of 3-nitrotyrosine is not the only marker of nitrative stress occurring during viral infections. We recently reported reactive nitrogen oxide-mediated nitration of nucleic acid in viral pneumonia (11). Nitration of DNA bases induced by $\mathrm{ONOO}^{-}$and other reactive species was previously described. Yermilov et al. first demonstrated in an in vitro study using calf thymus DNA incubated with synthetic $\mathrm{ONOO}^{-}$that $\mathrm{ONOO}^{-}$caused nitration of guanine to form 8-nitroguanine (72). The same group later showed that 8-nitroguanosine and 8-oxo-7,8dihydroguanosine formed in calf liver RNA after in vitro incubation with various reactive nitrogen species (73). Before direct evidence of guanine nitration by reactive nitrogen oxide species in vitro was available, clear evidence of DNA damage and mutation caused by $\mathrm{ONOO}^{-}$or NO during infections and inflammation had been obtained $(74,75)$. We subsequently provided the first report of NO-dependent guanine nitration during viral infection in vivo (11). We demonstrated extensive 8-nitroguanosine formation in bronchial and bronchoalveolar epithelial cells during influenza virus or $\mathrm{SeV}$ infection. The time profile of 8-nitroguanosine production correlated well with that of $\mathrm{NO}$ production and 3-nitrotyrosine generation after influenza virus infection. Moreover, 8-nitroguanosine staining colocalized with iNOS immunostaining and was absent in the airways of $\mathrm{iNOS}^{-/-}$mice infected with influenza virus.

After our report on 8-nitroguanosine formation during microbial infections appeared, additional data on guanine nitration in other infection models was published. For example, Pinlaor et al. demonstrated formation of 8-nitroguanine in the liver of hamsters infected with $O$. viverrini (12). More recently, 8-nitroguanine and 8-oxo-7,8-dihydro-2'-deoxyguanosine were found to be formed in gastric gland epithelial cells in patients and mice infected with H.pylori (Ref. 13; T. Akaike et al., unpublished observation). NO production and thus increased levels of reactive nitrogen oxides are known to occur in H. pylori infection $(76,77)$. Also, we recently observed formation of 8-nitroguanosine together with excessive production of NO in mouse liver infected with Salmonella (M.H. Zaki et al., unpublished observation).

All these data on nitration of proteins and nucleic acids suggest that nitrative stress is induced via $\mathrm{NO}$ overproduction triggered by infection and inflammation. The possible association of nitrative stress with viral pathogenesis prompted us to investigate the biological relevance of the nitration reactions as discussed below.

\section{Mechanism of nitrative stress-mediated viral patho- genesis}

Among the reactive intermediates derived from NO, $\mathrm{ONOO}^{-}$is a major cytotoxic agent with potent oxidizing and nitrating properties. $\mathrm{ONOO}^{-}$not only damages host tissues and cells in a nonselective manner, it also affects biomolecules of a host in a relatively selective fashion. 
For example, $\mathrm{ONOO}^{-}$activates matrix metalloproteinases (MMPs), enzymes that function in the disintegration of the extracellular matrix, which leads to tissue damage and remodeling $(78,79)$. MMPs are also known to have a critical role in apoptosis induction by means of proteolytic processing of TNF- $\alpha$ and FasL (78). We reported the unique redox regulation of MMP activity determined by a delicate balance between glutathione, an antioxidant that is abundant in lung, and reactive $\mathrm{ONOO}^{-}$(79). In addition to activation of MMPs, $\mathrm{ONOO}^{-}$readily inactivates both tissue inhibitor of MMP and $\alpha_{1}$-proteinase inhibitor, which is a major proteinase inhibitor in human plasma $(80,81)$. $\mathrm{ONOO}^{-}$also activates cyclooxygenase, a key enzyme for production of potent inflammatory prostaglandins (82). Thus, $\mathrm{ONOO}^{-}$ produced during virus-induced inflammation may promote tissue injury in numerous ways.

Other important functions of $\mathrm{ONOO}^{-}$include induction of apoptosis and necrosis, possibly via mitochondrial damage, which leads to cytochrome $c$ release (83). Lipid peroxidation and nitration of tyrosine residues of proteins by $\mathrm{ONOO}^{-}$may also be responsible for NO-mediated pathogenesis of viral infection. Although 3-nitrotyrosine formation was observed as a phenomenon related to NO-mediated viral pathogenesis, the exact role of 3-nitrotyrosine in viral pathogenesis as well as in other microbial infections is still obscure. Eiserich et al. showed that 3-nitrotyrosine was incorporated into $\alpha$-tubulin, which in turn distorted microtubule structures, and this change led to altered cellular morphogenesis and functions (84). 3-Nitrotyrosine formation may therefore contribute in part to cytotoxicity induced by reactive nitrogen oxides. However, a causal role for tyrosine nitration in inflammatory tissue injury has not yet been confirmed (85).

Nitration of guanine by $\mathrm{ONOO}^{-}$or other reactive species during viral infection is a new paradigm that may provide important insight into NO-mediated pathogenesis of pneumotropic viral infections. In fact, not only $\mathrm{ONOO}^{-}$but also $\mathrm{NO}_{2}$ formed via $\mathrm{H}_{2} \mathrm{O}_{2}$-peroxidase systems are shown to nitrate guanine in cell-free chemical reaction systems $(72,73)$. We observed extensive 8-nitroguanosine formation in airway epithelial cells, but not macrophages and neutrophils, during influenza virus infection in mice (11). This observation seemed to have pathological significance because influenza virus replicates in bronchiolar epithelial cells. However, whether formation of 8-nitroguanosine has any biological relevance in terms of pathogenesis was not clear until we recently identified certain unique features of 8-nitroguanosine $(11,15,86)$. We demonstrated that 8-nitroguanosine has a potent redox-active property and mutagenic potential. 8-Nitroguanosine is classified as a nitroarene on the basis of its chemical structure. Some nitroarenes possess redox-active properties that are activated by certain reductases such as cytochrome P450 reductase (87). This finding motivated us to investigate whether 8-nitroguanine or its derivative 8-nitroguanosine has redox activity that modulates biological reactions involving reductases. We discovered, via ESR analysis, that 8-nitroguanosine stimulated generation of $\mathrm{O}_{2}^{-}$from cytochrome P450 reductase and all isoforms of $\operatorname{NOS}(11,86)$. NOS utilizes NADPH as an electron donor, and the electrons that are accepted go through a cytochrome P450-reductase-like domain to a heme-containing oxidase domain, where the amino residue of L-arginine is oxidized to form NO. Under a specific condition, referred to as uncoupling of electron transport of NOSs, however, electron flow is disorganized, and electrons are transferred to molecular oxygen, which results in reduction of molecular oxygen to form $\mathrm{O}_{2}^{-}$. We clearly demonstrated that 8-nitroguanosine participated in this electron uncoupling, which thereby led to production of $\mathrm{O}_{2}^{-}$anion (Fig. 2). This process is pathophysiologically significant because $\mathrm{O}_{2}{ }^{-}$causes increased oxidative damage and $\mathrm{ONOO}^{-}$ formation. More important, expression of cytochrome P450 reductase was noted in the lung (88), and 8-

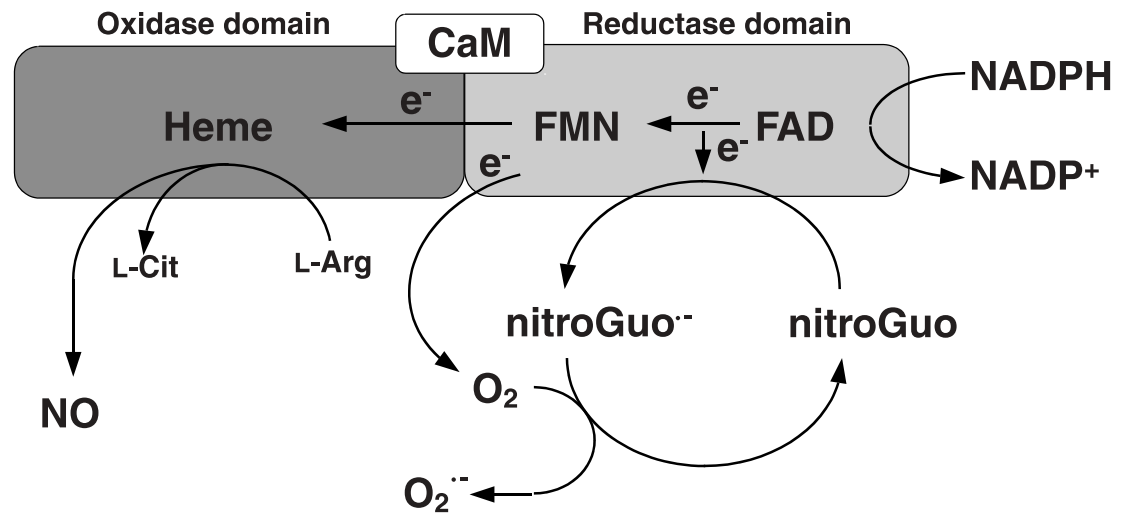

Fig. 2. Redox-active property of 8-nitroguanosine related to generation of $\mathrm{O}_{2}{ }^{--}$via activation of NOS. nitroGuo, 8-nitroguanosine; nitroGuo ${ }^{-}$, 8-nitroguanosine anion radical; CaM, calcium-calmodulin; FMN, flavin mononucleotide; FAD, flavin adenine dinucleotide; L-cit, L-citrulline; L-Arg, L-arginine. Adapted from Ref. 86. 
nitroguanosine was found colocalized with iNOS (11); these results favor the possibility of 8-nitroguanosinemediated $\mathrm{O}_{2}^{-}$generation in biological systems. Therefore, 8-nitroguanosine may not be simply a damaged nucleoside; rather, it may be an important redox cofactor implicated in diverse physiological and pathological events.

In addition to 8-nitroguanosine's having redox activity, it may serve as a mutagen for both virus and host tissue. A common mechanism of viral pathogenesis is escape from the host immune system via mutation. Our finding of increased mutation of $\mathrm{SeV}$ in the presence of 8-nitroguanosine may therefore point to another possible mechanism of nitrative stress-mediated viral pathogenesis (15). Moreover, we recently discovered that addition of 8-nitroguanosine to cells in culture under conditions of glucose starvation improved cell viability by inducing certain cytoprotective signals (T. Akuta et al., unpublished observation). This observation shed light on another unique property of 8-nitroguanosinemediated cell signaling, which may be closely relevant for viral pathogenesis. In the next section, we discuss nitrative stress-mediated viral mutation and its impact on the disease process in detail.

\section{Nitrative stress-induced microbial mutation and pathogenesis}

Modification of nucleic acids by reactive nitrogen and oxygen species is a common pathological event in several infectious diseases and inflammation. We already mentioned that during microbial infections the potent oxidizing and nitrating agent $\mathrm{ONOO}^{-}$is generated by reaction of $\mathrm{NO}$ with $\mathrm{O}_{2}^{-}$. $\mathrm{ONOO}^{-}$is a relatively stable compound (its half-life is about $1 \mathrm{~s}$ at physiological $\mathrm{pH}$ ) and can penetrate a cell's nucleus, which allows it to cause nitration and oxidation of nucleic acids and thereby DNA damage and strand breakage $(72,75)$. As a consequence of this DNA damage, mutation occurs in both host and pathogen. During infection, the spontaneous mutation of certain viruses, such as influenza virus and HIV, and the generation of new strains may derive from this mutagenic potential.

Several reports support the in vivo DNA modification and mutation caused by oxidative and nitrative stress. Human leukocytes producing $\mathrm{O}_{2}^{-}$but not leukocytes from patients with chronic granulomatous disease were previously shown to be mutagenic for S. enterica serovar Typhimurium TA100 (89). Wogan's group reported NO-mediated mutations in an endogenous hypoxanthine-guanine phosphoribosyltransferase (hprt) gene of murine macrophages expressing iNOS (90). Genetic analysis of the mutated gene induced by NO indicated that the NO-associated mutational spectrum was similar to that arising spontaneously, except for small deletions and insertions in the NO-induced mutant gene. The same group showed that mutagenicity was enhanced by NO overproduction in vivo, as indicated by mutation of an exogenously introduced lac $Z$ gene by using transgenic mice with a lacZ-containing pUR288 plasmid (91). Ohshima's group reported that p53 was inactivated by $\mathrm{ONOO}^{-}$, which may indirectly increase the occurrence of mutation related to oxidative damage of DNA (92). Excessive production of NO by iNOS induced by inflammatory cytokines, possibly through reactive nitrogen intermediates (particularly $\mathrm{ONOO}^{-}$), caused DNA damage and impaired DNA repair in human cholangiocarcinoma cells, as assessed by use of the comet assay; this result suggested NO-dependent development and progression of cholangiocarcinoma (93).

Viruses undergo spontaneous mutations that contribute to their adaptation and to evolution in the microbial environment. RNA viruses have a high mutation rate, ranging from $10^{-5}$ to $10^{-3}$ misincorporations/nucleotide site/round of copying, which is more than $10^{4}$ times higher than the rate for DNA viruses $(94,95)$. Thus, RNA viruses exist as highly heterogeneous populations called quasispecies, primarily because of the error-prone nature of the viral replicase. The low fidelity of RNA replication is believed to be due to a lack of proofreading and repair functions of RNA polymerase or reverse transcriptase $(96,97)$. Our recent study, however, showed that RNA is chemically unstable, so that base modifications via $\mathrm{ONOO}^{-}$-induced oxidation and nitration occur more readily in viral RNA than in eukaryotic DNA $(11,14)$. Thus, the higher incidence of erroneous viral RNA replication may also be partly due to RNA's greater susceptibility to oxidative damage compared with DNA.

\section{Development of a quantitative assay of mutation affected by nitrative stress}

Of prime concern is the availability of suitable methods of analysis of viral mutation that occurs during infection, which may be caused by oxidative and nitrative stress or other stimuli. Numerous methods exist for estimating viral mutation, including measurement of mutation frequencies of phenotypic variations such as temperature-sensitive growth, plaque morphology, host range, and pathogenicity. These measures, however, cannot be used for accurate and quantitative assessment of viral mutation, because the phenotypic variants often possess multiple base alterations in different genes. Identification of mutants that escape 
from neutralizing antibody is much more reliable for quantification of viral mutation. For example, escape of virus from a particular neutralizing monoclonal antibody occurs by a single base substitution, which leads to a single codon change in the epitope. The frequency of escape mutants thus determined in cultured cells in vitro was within the same range, approximately $10^{-4.5}$, for four negative-strand RNA viruses, that is, $\mathrm{SeV}$, vesicular stomatitis virus, Newcastle disease virus, and influenza virus $(98,99)$. Nevertheless, selection via antibody has not been proved to be definitive and reproducible because frequencies vary greatly, even within the same virus species, in that they depend on the antibodies used for selection (100). Moreover, this selection method cannot be used for in vivo studies because of the natural immunological selection of escape mutants during a host's immune response.

We therefore sought to develop a quantitative assay that would be applicable to in vitro study of mutagenesis (14). A recombinant $\mathrm{SeV}$ was constructed with an exogenous genome, green fluorescent protein (GFP), for the virus. Base substitutions occurring in the GFP in $\mathrm{SeV}$ are primarily neutral and do not affect viral replication and clearance of virus from the host. Viral mutation is readily quantified on the basis of the loss of strong fluorescence caused by GFP gene mutations. This GFP-based assay is convenient and useful for estimating in vivo viral mutagenesis. Using this GFP-SeV, we first demonstrated NO-mediated mutation in an RNA virus in vivo (14). Wild-type and $\mathrm{iNOS}^{-/}$mice were infected with GFP-SeV. The GFP-SeV mutants in the lung were isolated, and the GFP mutation rate was measured. GFP-
$\mathrm{SeV}$ mutation frequency increased significantly in wildtype mice compared with $\mathrm{iNOS}^{-/-}$mice as infection proceeded. The higher rate of GFP-SeV mutation in wild-type mice was accompanied by extensive 3-nitrotyrosine formation in the mouse lung, whereas tyrosine nitration in $\mathrm{iNOS}^{-/-}$mice was rare. Thus, higher production of NO in vivo was assumed to accelerate RNA virus mutation through formation of reactive nitrogen oxides such as $\mathrm{ONOO}^{-}$. In fact, the mutagenic potential of $\mathrm{ONOO}^{-}$for GFP-SeV was verified by in vitro $\mathrm{ONOO}^{-}$ treatment of GFP-SeV.

We further clarified our hypothesis concerning nitrative stress-mediated viral mutation by using GFP$\mathrm{SeV}$ replicated in iNOS-transfected SW480 (iNOSSW480) cells in culture (15). The mutation frequency of GFP-SeV propagated in iNOS-SW480 cells was markedly attenuated by treatment with 1 or $10 \mathrm{mM} \mathrm{L-}$ NMMA and was similar to the level of mutation frequency in SW480 cells without iNOS expression: that is, viral growth was not affected by NOS inhibition. It is important to note that RNA mutation occurred at the same rate in both the GFP and endogenous virus genes.

We also examined the possible association of nitrative stress with mutations occurring in $\mathrm{SeV}$ by analyzing nucleic acids for nitration, with a special focus on guanosine nitration (15). We observed much greater formation of 8-nitroguanosine, as detected immunohistochemically, in iNOS-SW480 cells than in parent SW480 cells (15). Confocal laser scanning of the immunostaining revealed that 8-nitroguanosine was localized mainly in the cytosol of iNOS-SW480 cells. This result was consistent with our previous finding of a

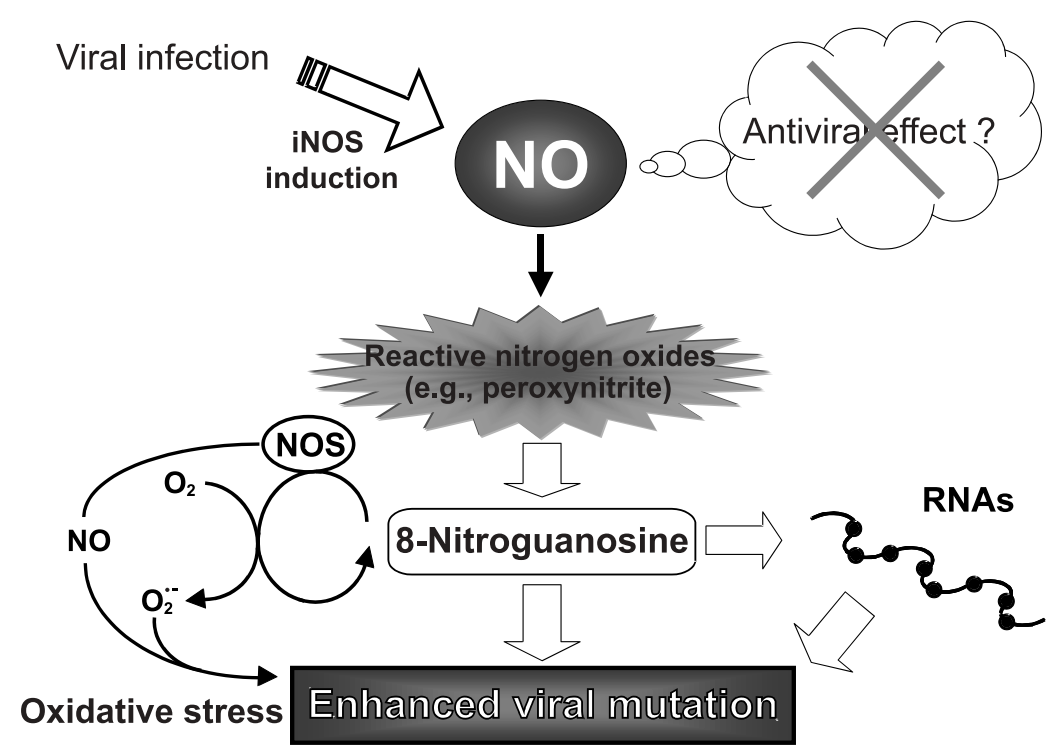

Fig. 3. Schematic drawing of NO-induced viral mutation involving 8-nitroguanosine formation and oxidative stress. 
similar intracellular localization of 8-nitroguanosine in bronchial epithelial cells of influenza virus-infected mouse lungs (11). The cytoplasmic localization of 8nitroguanosine may account for its formation in the nucleotide pool and RNA in the cellular cytosol. The mutagenic potential of 8-nitroguanosine for $\mathrm{SeV}$ was verified after direct addition of 8-nitroguanosine to cultured cells infected with GFP-SeV: the mutation frequency of the progeny virus was markedly elevated in a concentration-dependent fashion. More importantly, the mutation profile of the GFP gene in the GFP-SeV mutants induced by 8-nitroguanosine appeared to resemble that of mutants occurring in mouse lungs in vivo (with a predominant $\mathrm{C}$-to- $\mathrm{U}$ transition), when $\mathrm{NO}$ was produced in excess from iNOS. All these findings suggested that 8-nitroguanosine formed in vivo could indeed contribute to enhanced viral mutation induced by NO (15) (Fig. 3). Thus, nitrative stress generated by excessive production of NO in the host during pneumotropic virus infection causes viral mutation, which indirectly facilitates viral pathogenesis.

\section{Conclusion}

The pathogenic mechanism of many microbial infections is not always directly associated with microbial multiplication. Recent evidence of the generation of free

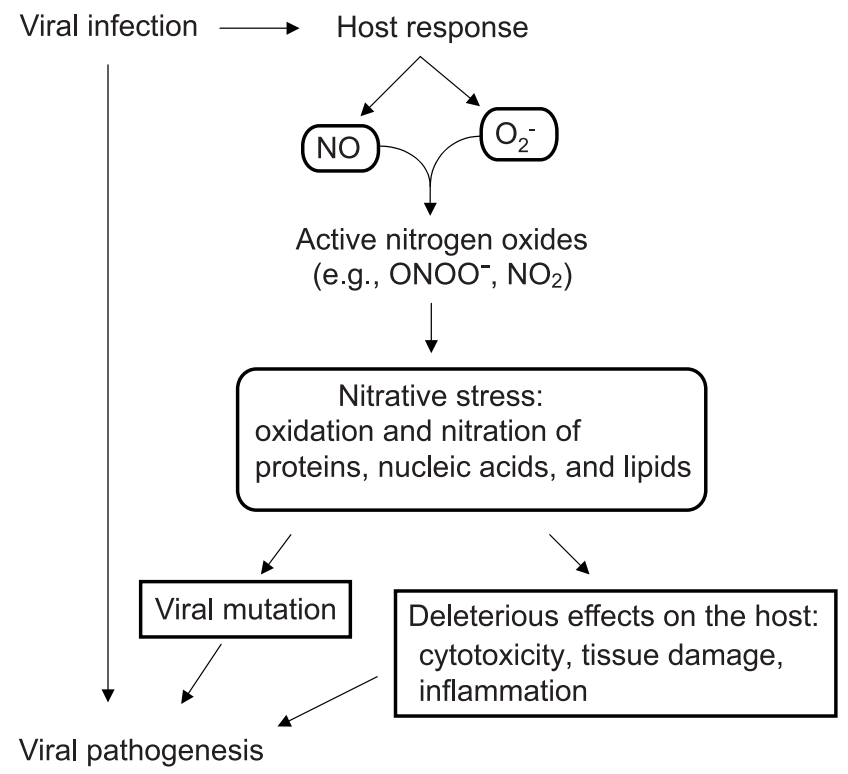

Fig. 4. Mechanism of viral pathogenesis related to free radicals generated during viral infection. The reaction between $\mathrm{NO}$ and $\mathrm{O}_{2}{ }^{-}$, which are produced as a host response to viral infection, results in formation of several reactive nitrogen oxides, which can oxidize and nitrate host proteins, lipids, and nucleic acids. Nitrative stress thus generated causes cellular damage in host tissue and inflammation and facilitates viral mutation. radicals, the most important one being $\mathrm{NO}$, and their relation to pathogenesis has provided insight for better understanding of microbial pathogenesis. In many cases, the basis of viral infection-mediated pathogenesis was direct cytotoxicity of reactive nitrogen oxides, which caused nitration and oxidation of a number of the host's biological molecules. Nitrative and oxidative stress thus generated during viral infection modulates the functioning of host cells and tissues in a manner that affects the pathogenesis (Fig. 4). Our recent studies of pneumotropic virus infections suggest that among various nitrated molecules, 8-nitroguanosine, which has several unique properties such as redox activity, cell signaling, and mutagenic potential, may play important roles in microbial pathogenesis. Future studies of the impact of nitrative stress-mediated effects on nucleic acids or other biological molecules may provide better understanding of the complex relationship between hosts and pathogens in infectious diseases.

\section{Acknowledgments}

The authors thank Ms. Judith B. Gandy for her excellent editing of the manuscript. This work was supported in part by Grants-in-Aid for scientific research from the Ministry of Education, Culture, Sports, Science, and Technology (MEXT) and the Ministry of Health, Labour, and Welfare of Japan.

\section{References}

1 Mayer B, Hemmens B. Biosynthesis and action of nitric oxide in mammalian cells. Trends Biochem Sci. 1997;22:477-481.

2 Moncada S, Palmer RM, Higgs EA. Nitric oxide physiology, pathophysiology and pharmacology. Pharmacol Rev. 1991;43: $109-142$.

3 Nathan C, Xie QW. Regulation of biosynthesis of nitric oxide. J Biol Chem. 1994;269:13725-13728.

4 Nathan CF, Hibbs JB Jr. Role of nitric oxide synthesis in macrophage antimicrobial activity. Curr Opin Immunol. 1991; 3:65-70.

5 Doi $\mathrm{T}$, Ando $\mathrm{M}$, Akaike $\mathrm{T}$, Suga $\mathrm{M}$, Sato $\mathrm{K}$, Maeda $\mathrm{H}$. Resistance to nitric oxide in Mycobacterium avium complex and its implication in pathogenesis. Infect Immun. 1993;61: 1980-1989.

6 Umezawa K, Akaike T, Fuji S, Suga M, Setoguchi K, Ozawa A, et al. Induction of nitric oxide synthesis and xanthine oxidase and their roles in the antimicrobial mechanism against Salmonella typhimurium infection in mice. Infect Immun. 1997;65:2932-2940.

7 James SL. Role of nitric oxide in parasitic infection. Microb Rev. 1995;59:533-547.

8 Nathan C, Xie QW. Nitric oxide synthases: roles, tolls, and controls. Cell. 1994;78:915-918.

9 Liew FY. Regulation of lymphocyte functions by nitric oxide. Curr Opin Immunol. 1995;7:396-399. 
10 Akaike T, Noguchi Y, Ijiri S, Setoguchi K, Suga M, Zheng YM, et al. Pathogenesis of influenza virus-induced pneumonia: involvement of both nitric oxide and oxygen radicals. Proc Natl Acad Sci USA. 1996;93:2448-2453.

11 Akaike T, Okamoto S, Sawa T, Yoshitake J, Tamura F, Ichimori $\mathrm{K}$, et al. 8-Nitroguanosine formation in viral pneumonia and its implication for pathogenesis. Proc Natl Acad Sci USA. 2003; 100:685-690.

12 Pinlaor S, Yongvanit P, Hiraku Y, Ma N, Semba R, Oikawa S, et al. 8-Nitroguanine formation in the liver of hamsters infected with Opisthorchis viverrini. Biochem Biophys Res Commun. 2003;309:567-571.

13 Ma N, Adachi Y, Hiraku Y, Horiki N, Horiike S, Imoto I, et al. Accumulation of 8-nitroguanine in human gastric epithelium induced by Helicobacter pylori infection. Biochem Biophys Res Commun. 2004;319:506-510.

14 Akaike T, Fujii S, Kato A, Yoshitake J, Miyamoto Y, Sawa T, et al. Viral mutation accelerated by nitric oxide production during infection in vivo. FASEB J. 2000;14:1447-1454.

15 Yoshitake J, Akaike T, Akuta T, Tamura F, Ogura T, Esumi H, et al. Nitric oxide as an endogenous mutagen for Sendai virus without antiviral activity. J Virol. 2004;78:8709-8719.

16 Reiss CS, Komatsu T. Does nitric oxide play a critical role in viral infections? J Virol. 1998;72:4547-4551.

17 Canthaboo C, Xing D, Wei XQ, Corbel MJ. Investigation of role of nitric oxide in protection from Bordetella pertussis respiratory challenge. Infect Immun. 2002;70:679-684.

18 Alam MS, Akaike T, Okamoto S, Kubota T, Yoshitake J, Sawa $\mathrm{T}$, et al. Role of nitric oxide in host defense in murine salmonellosis as a function of its antimicrobial and antiapoptotic activities. Infect Immun. 2002;70:3130-3142.

19 Adams LB, Franzblau SG, Vavrin Z, Hibbs JB Jr, Krahenbuhl JL. L-Arginine-dependent macrophage effector functions inhibit metabolic activity of Mycobacterium leprae. J Immunol. 1991; 147:1642-1646.

20 Denis M. In vivo modulation of atypical mycobacterial infection: adjuvant therapy increases resistance to Mycobacterium avium by enhancing macrophage effector functions. Cell Immunol. 1991;134:42-53.

21 Flesch IE, Hess JH, Kaufmann SH. NADPH diaphorase staining suggests a transient and localized contribution of nitric oxide to host defence against an intracellular pathogen in situ. Int Immunol. 1994;6:1751-1757.

22 Bermudez LE. Differential mechanisms of intracellular killing of Mycobacterium avium and Listeria monocytogenes by activated human and murine macrophages. The role of nitric oxide. Clin Exp Immunol. 1993;91:277-281.

23 Akaike T, Suga M, Maeda H. Free radicals in viral pathogenesis: molecular mechanisms involving superoxide and NO. Proc Soc Exp Biol Med. 1998;217:64-73.

24 Koprowski H, Zheng YM, Heber-Katz E, Fraser N, Rorke L, Fu $Z F$, et al. In vivo expression of inducible nitric oxide synthase in experimentally induced neurologic diseases. Proc Natl Acad Sci USA. 1993;90:3024-3027.

25 Zheng YM, Schafer MK, Weihe E, Sheng H, Corisdeo S, Fu ZF, et al. Severity of neurological signs and degree of inflammatory lesions in the brains of rats with Borna disease correlate with the induction of nitric oxide synthase. J Virol. 1993;67:5786-5791.

26 Karupiah G, Xie QW, Buller RM, Nathan C, Duarte C, MacMicking JD. Inhibition of viral replication by interferon- gamma-induced nitric oxide synthase. Science. 1993;261:14451458.

27 Akaike T, Weihe E, Schaefer M, Fu ZF, Zheng YM, Vogel W, et al. Effect of neurotropic virus infection on neuronal and inducible nitric oxide synthase activity in rat brain. J Neurovirol. 1995;1:118-125.

28 Fujii S, Akaike T, Maeda H. Role of nitric oxide in pathogenesis of herpes simplex virus encephalitis in rats. Virology. 1999;256: 203-212.

29 Bukrinsky MI, Nottet HS, Schmidtmayerova H, Dubrovsky L, Flanagan CR, Mullins ME, et al. Regulation of nitric oxide synthase activity in human immunodeficiency virus type 1 (HIV-1)-infected monocytes: implications for HIV-associated neurological disease. J Exp Med. 1995;181:735-745.

30 Majano PL, Garcia-Monzon C, Lopez-Cabrera M, Lara-Pezzi E, Fernandez-Ruiz E, Garcia-Iglesias C, et al. Inducible nitric oxide synthase expression in chronic viral hepatitis. Evidence for a virus-induced gene upregulation. J Clin Invest. 1998;101:13431352.

31 Zaragoza C, Ocampo CJ, Saura M, McMillan A, Lowenstein CJ. Nitric oxide inhibition of coxsackievirus replication in vitro. J Clin Invest. 1997;100:1760-1767.

32 Zaragoza C, Ocampo C, Saura M, Leppo M, Wei XQ, Quick R, et al. The role of inducible nitric oxide synthase in the host response to Coxsackievirus myocarditis. Proc Natl Acad Sci USA. 1998;95:2469-2474.

33 Mannick JB, Asano K, Izumi K, Kieff E, Stamler JS. Nitric oxide produced by human B lymphocytes inhibits apoptosis and Epstein-Barr virus reactivation. Cell. 1994;79:1137-1146.

34 Croen KD. Evidence for antiviral effect of nitric oxide. Inhibition of herpes simplex virus type 1 replication. J Clin Invest. 1993;91:2446-2452.

35 MacLean A, Wei XQ, Huang FP, Al-Alem UA, Chan WL, Liew FY. Mice lacking inducible nitric-oxide synthase are more susceptible to herpes simplex virus infection despite enhanced Th1 cell responses. J Gen Virol. 1998;79:825-830.

36 Drapier JC, Wietzerbin J, Hibbs JB Jr. Interferon-gamma and tumor necrosis factor induce the L-arginine-dependent cytotoxic effector mechanism in murine macrophages. Eur J Immunol. 1988;18:1587-1592.

37 Xie QW, Whisnant R, Nathan C. Promoter of the mouse gene encoding calcium-independent nitric oxide synthase confers inducibility by interferon gamma and bacterial lipopolysaccharide. J Exp Med. 1993;177:1779-1784.

38 Baskin H, Ellermann-Eriksen S, Lovmand J, Mogensen SC. Herpes simplex virus type 2 synergizes with interferon-gamma in the induction of nitric oxide production in mouse macrophages through autocrine secretion of tumour necrosis factoralpha. J Gen Virol. 1997;78:195-203.

39 Xie Q, Nathan C. The high-output nitric oxide pathway: role and regulation. J Leukoc Biol. 1994;56:576-582.

40 Visvanathan KV, Goodbourn S. Double-stranded RNA activates binding of NF-kappa $\mathrm{B}$ to an inducible element in the human beta-interferon promoter. EMBO J. 1989;8:1129-1138.

41 Kamijo R, Harada H, Matsuyama T, Bosland M, Gerecitano J, Shapiro D, et al. Requirement for transcription factor IRF-1 in NO synthase induction in macrophages. Science. 1994;263: $1612-1615$.

42 Martin E, Nathan C, Xie QW. Role of interferon regulatory factor 1 in induction of nitric oxide synthase. J Exp Med. 
1994;180:977-984.

43 Saura M, Zaragoza C, Bao C, McMillan A, Lowenstein CJ. Interaction of interferon regulatory factor-1 and nuclear factor $\kappa \mathrm{B}$ during activation of inducible nitric oxide synthase transcription. J Mol Biol. 1999;289:459-471.

44 Paludan SR, Ellermann-Eriksen S, Mogensen SC. NF-kappaB activation is responsible for the synergistic effect of herpes simplex virus type 2 infection on interferon-gamma-induced nitric oxide production in macrophages. J Gen Virol. 1998; 79:2785-2793.

45 Cunha FQ, Moncada S, Liew FY. Interleukin-10 (IL-10) inhibits the induction of nitric oxide synthase by interferon-gamma in murine macrophages. Biochem Biophys Res Commun. 1992; 182:1155-1159.

46 Vodovotz Y, Bogdan C, Paik J, Xie QW, Nathan C. Mechanisms of suppression of macrophage nitric oxide release by transforming growth factor beta. J Exp Med. 1993;178:605-613.

47 Bogdan C, Vodovotz Y, Paik J, Xie QW, Nathan C. Mechanism of suppression of nitric oxide synthase expression by interleukin-4 in primary mouse macrophages. J Leukoc Biol. 1994; 55:227-233

48 Corraliza IM, Soler G, Eichmann K, Modolell M. Arginase induction by suppressors of nitric oxide synthesis (IL-4, IL-10 and $\left.\mathrm{PGE}_{2}\right)$ in murine bone-marrow-derived macrophages. Biochem Biophys Res Commun. 1995;206:667-673.

49 Gotoh T, Sonoki T, Nagasaki A, Terada K, Takiguchi M, Mori M. Molecular cloning of cDNA for nonhepatic mitochondrial arginase (arginase II) and comparison of its induction with nitric oxide synthase in a murine macrophage-like cell line. FEBS Lett. 1996;395:119-122.

50 Akaike T, Maeda H. Nitric oxide in influenza. In: Fang FC, editor. Nitric oxide in infection. New York: Kluwer Academic /Plenum Publishers; 1999. p. 397-415.

51 Ohmori Y, Hamilton TA. IL-4-induced STAT6 suppresses IFNgamma-stimulated STAT1-dependent transcription in mouse macrophages. J Immunol. 1997;159:5474-5482.

52 Paludan SR, Ellermann-Eriksen S, Lovmand J, Mogensen SC. Interleukin-4-mediated inhibition of nitric oxide production in interferon- $\gamma$-treated and virus-infected macrophages. Scand J Immunol. 1999;49:169-176.

53 Adamson DC, Kopnisky KL, Dawson TM, Dawson VL. Mechanisms and structural determinants of HIV-1 coat protein, gp41-induced neurotoxicity. J Neurosci. 1999;19:64-71.

54 Hori K, Burd PR, Furuke K, Kutza J, Weih KA, Clouse KA. Human immunodeficiency virus-1-infected macrophages induce inducible nitric oxide synthase and nitric oxide (NO) production in astrocytes: astrocytic NO as a possible mediator of neural damage in acquired immunodeficiency syndrome. Blood. 1999; 93:1843-1850.

55 Rostasy K, Monti L, Yiannoutsos C, Kneissl M, Bell J, Kemper TL, et al. Human immunodeficiency virus infection, inducible nitric oxide synthase expression, and microglial activation: pathogenetic relationship to the acquired immunodeficiency syndrome dementia complex. Ann Neurol. 1999;46:207-216.

56 Tsutsumi H, Takeuchi R, Ohsaki M, Seki K, Chiba S. Respiratory syncytial virus infection of human respiratory epithelial cells enhances inducible nitric oxide synthase gene expression. J Leukoc Biol. 1999;66:99-104.

57 Mordvintcev P, Mulsch A, Busse R, Vanin A. On-line detection of nitric oxide formation in liquid aqueous phase by electron paramagnetic resonance spectroscopy. Anal Biochem. 1991; 199:142-146.

58 Yoshimura T, Yokoyama H, Fujii S, Takayama F, Oikawa K, Kamada H. In vivo EPR detection and imaging of endogenous nitric oxide in lipopolysaccharide-treated mice. Nat Biotechnol. 1996;14:992-994.

59 Kreil TR, Eibl MM. Nitric oxide and viral infection: NO antiviral activity against a flavivirus in vitro, and evidence for contribution to pathogenesis in experimental infection in vivo. Virology. 1996;219:304-306.

60 Adler H, Beland JL, Del-Pan NC, Kobzik L, Brewer JP, Martin TR, et al. Suppression of herpes simplex virus type 1 (HSV-1)induced pneumonia in mice by inhibition of inducible nitric oxide synthase (iNOS, NOS2). J Exp Med. 1997;185:15331540 .

61 Tanaka K, Nakazawa H, Okada K, Umezawa K, Fukuyama N, Koga Y. Nitric oxide mediates murine cytomegalovirusassociated pneumonitis in lungs that are free of the virus. J Clin Invest. 1997;100:1822-1830.

62 Tanaka K, Noda S, Sawamura S, Kabir AM, Koga Y. Nitric oxide targets bronchiolar epithelial cells in murine cytomegalovirus-associated disease in lungs that are free of the virus. Arch Virol. 2001;146:1499-1515.

63 Kandemir O, Polat A, Kaya A. Inducible nitric oxide synthase expression in chronic viral hepatitis and its relation with histological severity of disease. J Viral Hepat. 2002;9:419-423.

64 Beckman JS, Beckman TW, Chen J, Marshall PA, Freeman BA. Apparent hydroxyl radical production by peroxynitrite: implications for endothelial injury from nitric oxide and superoxide. Proc Natl Acad Sci USA. 1990;87:1620-1624.

65 Beckman JS, Koppenol WH. Nitric oxide, superoxide and peroxynitrite: the good, the bad, and ugly. Am J Physiol. 1996;271:C1424-C1437.

66 Rubbo H, Darley-Usmar V, Freeman BA. Nitric oxide regulation of tissue free radical injury. Chem Res Toxicol. 1996;9:809-820.

67 Eiserich JP, Cross CE, Jones AD, Halliwell B, van der Vliet A. Formation of nitrating and chlorinating species by reaction of nitrite with hypochlorous acid. A novel mechanism for nitric oxide-mediated protein modification. J Biol Chem. 1996;271: 19199-19208.

68 Byun J, Henderson JP, Mueller DM, Heinecke JW. 8-Nitro-2'deoxyguanosine, a specific marker of oxidation by reactive nitrogen species, is generated by the myeloperoxidase-hydrogen peroxide-nitrite system of activated human phagocytes. Biochemistry. 1999;38:2590-2600.

69 Barreiro E, Comtois AS, Gea J, Laubach VE, Hussain SN. Protein tyrosine nitration in the ventilatory muscles: role of nitric oxide synthases. Am J Respir Cell Mol Biol. 2002;26:438-446.

70 Oda T, Akaike T, Hamamoto T, Suzuki F, Hirano T, Maeda H. Oxygen radicals in influenza-induced pathogenesis and treatment with pyran polymer-conjugated SOD. Science. 1989; 244:974-976.

71 Akaike T, Ando M, Oda T, Doi T, Ijiri S, Araki S, et al. Dependence on $\mathrm{O}_{2}^{-}$generation by xanthine oxidase of pathogenesis of influenza virus infection in mice. J Clin Invest. 1990;85:739-745.

72 Yermilov V, Rubio J, Ohshima H. Formation of 8-nitroguanine in DNA treated with peroxynitrite in vitro and its rapid removal from DNA by depurination. FEBS Lett. 1995;376:207-210.

73 Masuda M, Nishino H, Oshima H. Formation of 8-nitro- 
guanosine in cellular RNA as a biomarker of exposure to reactive nitrogen species. Chem Biol Interact. 2002;139:187197.

74 deRojas-Walker T, Tamir S, Ji H, Wishnok JS, Tannenbaum SR. Nitric oxide induces oxidative damage in addition to deamination in macrophage DNA. Chem Res Toxicol. 1995;8:473-477.

75 Douki T, Cadet J. Peroxynitrite mediated oxidation of purine bases of nucleosides and isolated DNA. Free Radic Res. 1996;24:369-380.

76 Shiotani A, Iishi H, Kumamoto M, Nakae Y. Helicobacter pylori infection and increased nitrite synthesis in the stomach. Inflammation and atrophy connections. Dig Liver Dis. 2004; $36: 327-332$.

77 Nam KT, Oh SY, Ahn B, Kim YB, Jang DD, Yang KH, et al. Decreased Helicobacter pylori associated gastric carcinogenesis in mice lacking inducible nitric oxide synthase. Gut. 2004;53: $1250-1255$.

78 Okamoto T, Akuta T, Tamura F, van der Vleit A, Akaike T. Molecular mechanism for activation and regulation of matrix metalloproteinases during infections and respiratory inflammation. Biol Chem. 2004;385:997-1006.

79 Okamoto T, Akaike T, Sawa T, Miyamoto Y, van der Vleit A, Maeda $\mathrm{H}$. Activation of matrix metalloproteinases by peroxynitrite-induced protein $S$-glutathiolation via $S$-oxide formation. J Biol Chem. 2001;276:29596-29602.

80 Moreno JJ, Pryor WA. Inactivation of alpha 1-proteinase inhibitor by peroxynitrite. Chem Res Toxicol. 1992;5:425-431.

81 Frears ER, Zhang Z, Blake DR, O'Connell JP, Winyard PG. Inactivation of tissue inhibitor of metalloproteinase-1 by peroxynitrite. FEBS Lett. 1996;381:21-24.

82 Landino LM, Crews BC, Timmons MD, Morrow JD, Marnett LJ. Peroxynitrite, the coupling product of nitric oxide and superoxide, activates prostaglandin biosynthesis. Proc Natl Acad Sci USA. 1996;93:15069-15074.

83 Hortelano S, Alvarez AM, Bosca L. Nitric oxide induces tyrosine nitration and release of cytochrome $c$ preceding an increase of mitochondrial transmembrane potential in macrophages. FASEB J. 1999;13:2311-2317.

84 Eiserich JP, Estevez AG, Bamberg TV, Ye YZ, Chumley PH, Beckman JS, et al. Microtubule dysfunction by posttranslational nitrotyrosination of $\alpha$-tubulin: a nitric oxide-dependent mechanism of cellular injury. Proc Natl Acad Sci USA. 1999;96:63656370.

85 Baldus S, Castro L, Eiserich JP, Freeman BA. Is NO news bad news in acute respiratory distress syndrome? Am J Respir Crit Care Med. 2001;163:308-310.
86 Sawa T, Akaike T, Ichimori K, Akuta T, Kaneko K, Nakayama $\mathrm{H}$, et al. Superoxide generation mediated by 8-nitroguanosine, a highly redox active nucleic acid derivative. Biochem Biophys Res Commun. 2003;311:300-306.

87 Mason RP. Free-radical intermediates in the metabolism of toxic chemicals. In: Pryor WA, editor. Free radicals in biology. New York: Academic Press; 1982. p. 161-222.

88 Hall PM, Stupans I, Burgess W, Birkett DJ, McManus ME. Immunohistochemical localization of NADPH-cytochrome P450 reductase in human tissues. Carcinogenesis. 1989;10:521530.

89 Weitzman SA, Stossel TP. Mutation caused by human phagocytes. Science. 1981;212:546-547.

90 Zhuang JC, Lin C, Lin D, Wogan GN. Mutagenesis associated with nitric oxide production in macrophages. Proc Natl Acad Sci USA. 1998;95:8286-8291.

91 Gal A, Wogan GN. Mutagenesis associated with nitric oxide production in transgenic SJL mice. Proc Natl Acad Sci USA. 1996;93:15102-15107.

92 Calmels S, Hainaut P, Ohshima H. Nitric oxide induces conformational and functional modifications of wild-type p53 tumor suppressor protein. Cancer Res. 1997;57:3365-3369.

93 Jaiswal M, LaRusso NF, Burgart LJ, Gores GJ. Inflammatory cytokines induce DNA damage and inhibit DNA repair in cholangiocarcinoma cells by a nitric oxide-dependent mechanism. Cancer Res. 2000;60:184-190.

94 Holland J, Spindler K, Horodyski F, Grabau E, Nichol S, VandePol S. Rapid evolution of RNA genomes. Science. 1982; 215:1577-1585.

95 Drake JW. Rates of spontaneous mutation among RNA viruses. Proc Natl Acad Sci USA. 1993;90:4171-4175.

96 Domingo E, Menendez-Arias L, Holland JJ. RNA virus fitness. Rev Med Virol. 1997;7:87-96.

97 Leider JM, Palese P, Smith FI. Determination of the mutation rate of a retrovirus. J Virol. 1988;62:3084-3091.

98 Portner A, Webster RG, Bean WJ. Similar frequencies of antigenic variants in Sendai, vesicular stomatitis, and influenza A viruses. Virology. 1980;104:235-238.

99 Nishikawa K, Isomura S, Suzuki S, Watanabe E, Hamaguchi M, Yoshida T, et al. Monoclonal antibodies to the $\mathrm{HN}$ glycoprotein of Newcastle disease virus. Biological characterization and use for strain comparisons. Virology. 1983;130:318-330.

100 Smith DB, Inglis SC. The mutation rate and variability of eukaryotic viruses: an analytical review. J Gen Virol. 1987;68:2729-2740. 